To Cite: Mellalou A, Mouaky A, Samba Vall CM, Yui Yip L, Bacaoui A, Outzourhit A, 2021. Performance of an Air Solar Collector With Different Absorber Modifications Under the Climatic Conditions of Marrakech-Morocco. Journal of the Institute of Science and Technology, 11(3): 2195-2207.

\title{
Performance Of An Air Solar Collector With Different Absorber Modifications Under The Climatic Conditions Of Marrakech-Morocco
}

\section{Abderrahman MELLALOU ${ }^{*}$, Ammar MOUAKY ${ }^{2}$, Cheikh Mohamed SAMBA VALL ${ }^{1}$, Lau YUI- YIP $^{3}$, Abdelaziz BACAOUI $^{4}$, Abdelakader OUTZOURHIT ${ }^{1}$}

ABSTRACT: Solar air collectors are commonly used in a variety of domestic and industrial fields. The simple design and low maintenance cost are among their advantages compared to other solar collectors. However, the main challenge of this type of collector is the low heat transfer coefficient. In this work, the effect of different designs of the absorber plate (waved and V corrugated modification) on the thermal performances, the heat exchange effectiveness and the air outlet temperature of a Double-Pass Parallel-Flow air solar collector was investigated under the solar radiation of MarrakechMorocco in a clear day and for three different mass flows rates $\left(0.008 \mathrm{~kg} \mathrm{~s}^{-1}, 0.012 \mathrm{~kg} \mathrm{~s}^{-1}\right.$ and $0.016 \mathrm{~kg}$ $\mathrm{s}^{-1}$ ). The numerical study was done using Computational Fluid Dynamics (CFD) by the mean of ANSYS Fluent 16.0. The obtained results showed that the $\mathrm{V}$ corrugated modification is the most efficient one with efficiency equal to $76.92 \%$ and $87.97 \%$ under the lowest and highest mass flow, respectively.

Keywords: double-pass parallel-flow air solar collector (DPPF), efficiency, solar energy, solar load model

\footnotetext{
${ }^{1}$ Abderrahman MELLALOU (Orcid ID: 0000-0003-2610-7626), Cheikh Mohamed SAMBA VALL( $\underline{\text { Orcid ID: 1687- }}$ 5716-8609-1702), Abdelakader OUTZOURHIT (Orcid ID: 0000-0002-6871-4670), Materials, Energy and Environment Laboratory (LaMEE), Faculty of Sciences Semlalia, University Cadi Ayyad, Marrakech Morocco;

${ }^{2}$ Ammar MOUAKY (Orcid ID: 0000-0002-6054-3942), Green Energy Park (IRESEN, UM6P), Km 2 Route Régionale R206, Benguerir, Morocco;

${ }^{3}$ Lau YUI-YIP (Orcid ID: 0000-0002-4011-5625), Division of Business and Hospitality Management, College of Professional and Continuing Education, The Hong Kong Polytechnic University;

${ }^{4}$ Abdelaziz BACAOUI (rcid ID: 0000-0002-3867-2836)

*Sorumlu Yazar/Corresponding Author: Abderrahman MELLALOU, e-mail: abderrahman.mellalou@gmail.com

This study was presented in the conference named 'International conference on Energy, Environement and Storage of Energy' ICEESEN2020 (Oral presentation). Moreover, it was selected for publication in this journal, "Igdir University Journal of the Instutitue of Science and Technology". During the period between 19-21 November 2020 in Turkey.
} 


\section{INTRODUCTION}

Solar energy has received considerable attention compared to other alternatives sources, as an efficient and promising source of energy to meet the continuous increase in the world energy demand (Ekechukwu and Norton 1999; Vengadesan and Senthil 2020). Solar energy can be either directly converted to low or high temperature heat or to electricity through photovoltaic panels. Moreover, it is a free and clean source of energy, which helps in decreasing global warming. However, the conversion of solar rays into useful energy needs specific devices with high efficiency.

Air solar collectors are used in a variety of industrial processes for heat production, such as materials treatments, space heating, biomass valorization using thermochemical methods and agricultural drying (Ekechukwu and Norton 1999; Güler et al. 2020). They represent the main devices in the indirect solar drying, where the circulating air is heated and then driven into the drying chamber. Several air solar collector configurations exist. They are characterized by their low cost, simple design and structure. However, air solar collectors have low thermal efficiency related to their low heat transfer coefficient. Various researches have been conducted in order to enhance the thermal performance of air solar collectors by increasing this key factor (Kishk, ElGamal, and ElMasry 2019; Vengadesan and Senthil 2020; Yadav and Bhagoria 2014). Several modifications have been performed over the absorber plate of the air solar collector with the aim of enhancing the heat transfer.

Adding artificial roughness is an efficient way to increase the heat transfer coefficient of the collector by breaking the laminar sub-layer and creating turbulence over the absorber plate. However, artificial roughness has also some disadvantages related to friction losses. Thus, it is necessary to conduct studies of different types of artificial roughness and optimize the key factors of heat transfer and pressure losses. Different geometric shapes and forms of artificial roughness were proposed and investigated, such as inclined fins, triangular fins, circular fins, elliptical shaped fins and rectangular fins (Vengadesan and Senthil 2020). Chaube et al. (2006)conducted a computational analysis on the artificial roughness implementation in the form of ribs on the absorber plate under turbulent flow (Reynolds number range 3000-20,000), in order to highlight its impact on the heat transfer enhancement and flow characteristics. Their analysis showed that the peak in heat transfer coefficient occurs at the point of reattachment of the separated flow. Moreover, a significant enhancement of the heat transfer was found compared to that of a smooth surface. The highest heat transfer is achieved with chamfered ribs, but the best performance index is found with a rectangular rib of size $3 \times 5 \mathrm{~mm}$. Yadav et al. (2014) conducted a numerical investigation on the heat transfer and fluid flow characteristics of fully developed turbulent flow in a rectangular duct having repeated transverse square-sectioned rib roughness of different characteristics (Relative roughness height and Relative roughness pitch). Twelve different configurations of square sectioned rib were considered in their study. It was found that the square-sectioned transverse rib roughened duct with relative roughness pitch and relative roughness height of 10.71 and 0.042 respectively, offers the best thermo-hydraulic performance parameter (high transfer coefficient) in the investigated range of parameters. However enlarging the parameters range of the studied ribs may lead to different results. Therefore enhancing the thermo-hydraulic performances of the air solar collector. On the other hand, Pashchenko et al. (2018) studied the influence of the design and technological variable on the thermal and aerodynamic processes taking place in a solar air heater having light-absorbing L-shaped fins. They found that the maximum thermo-aerodynamic characteristic was found for a solar air collector with a finned light absorbing surface of 1.92 and a minimum fin pitch of $30 \mathrm{~mm}$. Yaday et al. (2013) performed a CFD analysis of heat transfer enhancement and flow characteristics due to circular transverse wire rib 
roughness on the absorber plate of an air solar collector. They investigated the effect of relative roughness pitch (P/e) and relative roughness height (e/D) of a circular rib on the thermal enhancement factor. They found that ribs of small diameters create intense turbulence, resulting in greater increase in the heat transfer over the absorber plate. Moreover, they reported that the circular transverse wire rib roughness with $\mathrm{P} / \mathrm{e}=10.71$ and $\mathrm{e} / \mathrm{D}=0.042$ provides better thermal enhancement factor for the studied range of parameters and thus can be employed for heat transfer augmentation. An innovative idea from the environmental point of view using recyclable aluminum cans as absorber plate for air solar collector was proposed by Kishk et al.(2019). They designed and investigated the effectiveness of recyclable aluminum cans in the fabrication of a solar collector for drying purposes. Their results revealed that the thermal efficiency of the designed solar collector increased considerably from 25 to $63 \%$ when the airflow rate increased from 15 to $45 \mathrm{~m}^{3} \mathrm{~h}^{-1}$.

Beside the absorber surface modification, air solar collector types play an important role in the thermal performances enhancement. Several types of air solar collectors exist and have been widely studied. Vengadesan et al. (2020) critically reviewed in their work the recent studies on thermal performance enhancement of different types of flat-plate solar air collectors, namely: single pass, multiple-passes, porous absorbers, air-jet impingement on absorber surface, integration of heat storage materials, dual-purpose hybrid collectors and hybrid photovoltaic/thermal solar collectors. Lower thermal heat transfer is not only limited to the convective heat transfer coefficient but also to the conductive heat transfer, which also has a significant effect. In single pass solar collector heat is transferred from the upper side of the absorber to a very lower layer of the air by conductive heat transfer mechanism when the velocity of the air is very low. While, in double pass solar air heaters, in addition to the conductive heat transfer, an advection heat transfer occurs at the lower side of the absorber plate which by consequence intensifies the heat transfer coefficient. Double-pass solar air collectors increase the air's outlet temperature by passing the air over and underneath the absorber plate, hence improving the heat absorption and transfer by both passes (Vengadesan and Senthil 2020). Singh et al. (2018) made a computational fluid dynamics (CFD) analysis of various designs of a curved solar air heater in order to study the dynamic thermal performance of smooth and the effect of different types of artificial roughness on the absorber plate. They found that a solar air heater with a curved plate of V-corrugated single pass had the highest thermal efficiency of $91.93 \%$, which allowed the air inlet temperature to increase by $32.05 \%$.

A number of studies in this area have been carried out, but very few attempts of numerical investigation of different artificial roughness shapes and forms have been made so far for double pass solar collector, due to the complexity of flow patterns and computational limitations. In the present work velocity and temperature patterns inside a double pass parallel flow air solar collector (DPPF) are numerically determined. Moreover, the thermal performance and the heat exchange effectiveness of the (DPPF) with different absorber modification, under the solar radiation of Marrakech $\left(31.6295^{\circ}\right.$ $\mathrm{N}, 7.9811^{\circ} \mathrm{W}$ ) under different flow rates are also investigated.

\section{MATERIALS AND METHODS}

\section{CFD Simulation}

Computational fluid dynamics (CFD) enable to solve complex physics problems with different geometry with high accuracy. ANSYS fluent software was used to simulate and study the thermal behavior of air solar collector. According to simulation results, the most convenient design of air solar collector will be selected for manufacturing. 


\section{Air solar collector}

A basic solar air collector is constituted of three main parts having a great impact on the thermal energy transferred to air which are: i) the insulation characterized by high thermal resistance in order to avoid heat losses during the air passage through the solar collector. Wood is usually suitable due to its thermal insulation characteristics. ii) The cover, characterized by a high transmission factor of the solar spectrum to allow the penetration of solar radiation inside the solar collector. Moreover, the cover should possess a low transmittance of infrared radiation and low heat absorptivity in order to trap the re-radiated heat from the absorber. Glass and plastics (Polycarbonate) are the main materials usually used as a transparent sheet for solar air collector cover. iii) The absorber plate is the essential component and all modifications seeking an enhancement of the thermal performance of air solar collector were carried out on the absorber plate. This plate is usually a metal sheet of different thicknesses; it can be painted in black in order to increase its absorption and emissivity to enhance the thermal transfer to the surrounded air.

In the present study, four different configurations were studied in order to increase the performance of the air solar collector. In the first step, a basic double pass-parallel flow solar air collector (DPPF) composed of a flat plate absorber was designed. The overall dimensions of this DPPF collector are $500 \times 300 \times 100 \mathrm{~mm}^{3}$ with an absorber plate of $400 \mathrm{~mm}$ length, $300 \mathrm{~mm}$ width and $2 \mathrm{~mm}$ thickness placed at $50 \mathrm{~mm}$ from the bottom of DPPF collector. The inlet of parallel-pass solar air solar collector is of square cross-section with an edge of $40 \mathrm{~mm}$ (Figure 1). The geometry of the DPPF collector was modeled in Solidworks software then imported to the geometry module of ANSYS fluent. In the second, different modifications starting by waved absorber of geometric waves parallel and perpendicular to the flow direction respectively were implemented as presented in Figures 2-a and 2-b. Then V-corrugated modification was added to the upper side of the absorber plate as it can be seen in Figure 2-c. These modifications were made to the absorber plate in order to evaluate their impact on the thermal behavior of the DPPF collector. The optimum design of the absorber plate will be adapted for manufacturing.

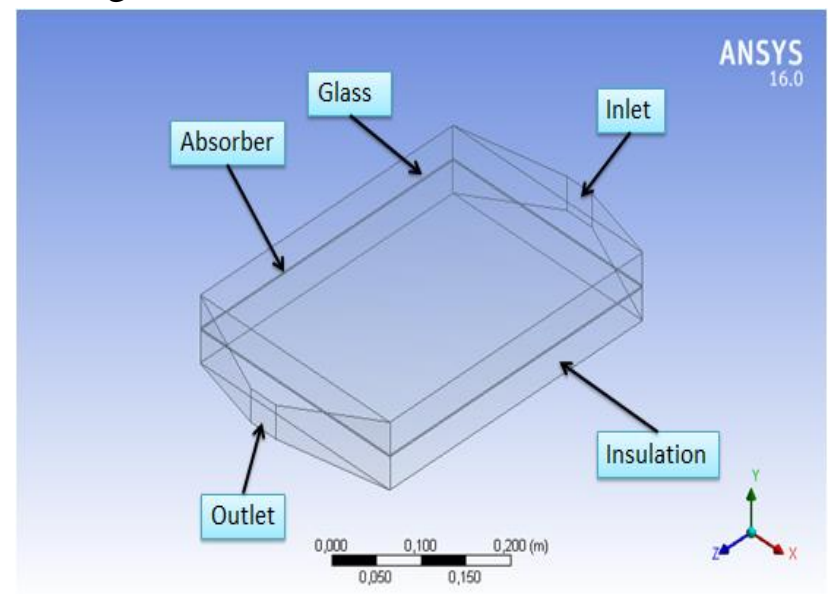

Figure 1. Basic air solar collector with flat plat collector

The outlet temperatures of all air solar collectors were compared to determine the effect of absorber modification on DPPF collector efficiency. The generated mesh for the four DPPF solar air collectors is presented in Figure 3. As it can be seen in this Figure, finer meshing was generated in zones near the absorber plate and air inlet and outlet in order to obtain reliable results. In the CFD simulation part, aluminum was selected as the absorber's material and wood as the insulation material, 
the values of different properties of these selected materials are given in Table 1 . In the numerical simulation of the DPPF solar collector, steady-state conditions were considered.

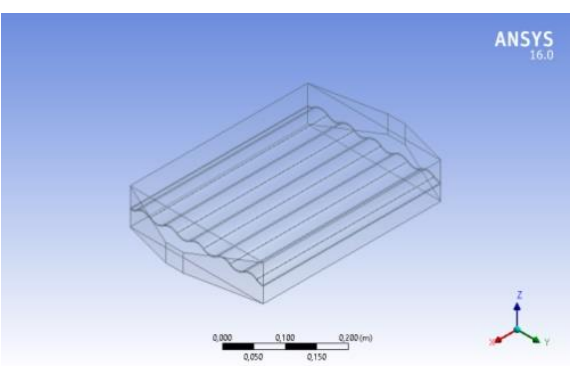

(a)

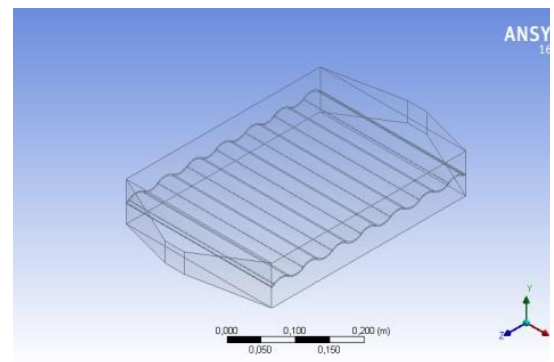

(b)

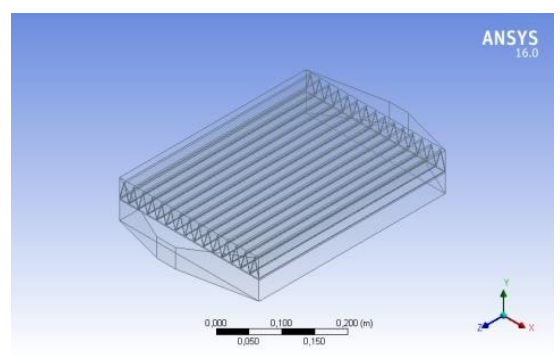

(c)

Figure 2. Air solar collector configurations (a) with waves parallel (b) waves perpendicular to the flow direction (c) with $\mathrm{V}$-corrugated modification

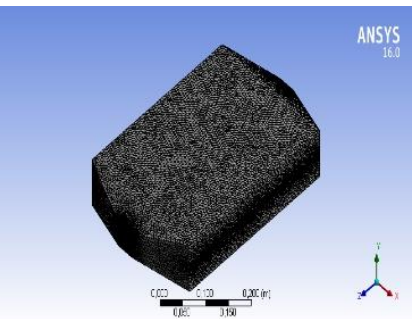

(a)

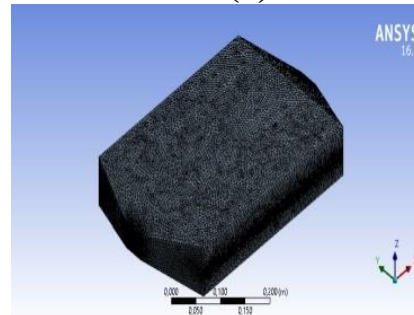

(b)

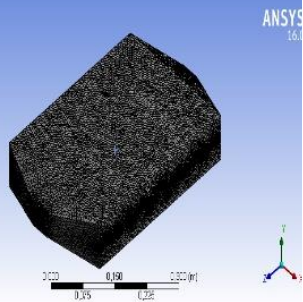

(c)

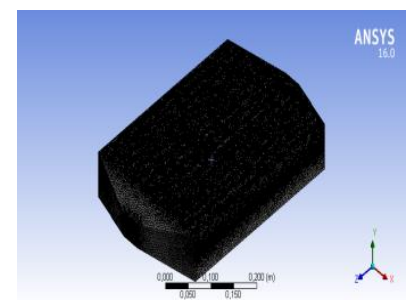

(d)

Figure 3. Mesh configuration of solar air collector (a) configuration 1, (b) configuration 2, (c) configuration 3 and (d) configuration 4

\section{Governing equations}

In this study, a solar load model was used to calculate the radiation effect from sun's rays that penetrate the computational domain, by the mean of the solar calculator utility, taking into consideration the geographic characteristics of the site (Marrakech). The radiative transfer equation was modeled by the Discrete Transfer Radiation Model (DTRM), in order to describe the radiation phenomena of all the rays crossing into the domain cells. The basic governing equation of fluid flow and heat transfer are the Navier-Stokes equations, which are derived from the basic mass conservation and continuity equations applied to fluids properties. These equations were iteratively solved using CFD solvers internally. These equations are as follow:

- Mass conservation equation:

$$
\frac{\partial \rho}{\partial \mathrm{t}}+\frac{\partial\left(\rho v_{\mathrm{i}}\right)}{\partial \mathrm{x}_{\mathrm{i}}}=0
$$

- Momentum equation:

$$
\frac{\partial\left(\rho v_{i} v_{j}\right)}{\partial x_{j}}=\frac{-\partial P}{\partial x_{i}}+\frac{\partial}{\partial x_{j}}\left(\mu\left(\frac{\partial v_{i}}{\partial x_{j}}+\frac{\partial v_{j}}{\partial x_{i}}\right)-\frac{2}{3} \mu \frac{\partial v_{k}}{\partial x_{k}} \delta_{i j}\right)
$$


Table 1. DPPF air solar collector components proprieties

\begin{tabular}{lc}
\hline Parameters & Values \\
\hline Specific heat of glass cover & $800\left(\mathrm{~J} \mathrm{~kg}^{-1} \mathrm{~K}^{-1}\right)$ \\
Specific heat of absorber plate & $871\left(\mathrm{~J} \mathrm{~kg}^{-1} \mathrm{~K}^{-1}\right)$ \\
Specific heat of insulation material & $2310\left(\mathrm{~J} \mathrm{~kg}^{-1} \mathrm{~K}^{-1}\right)$ \\
Thermal conductivity of glass cover & $1.02\left(\mathrm{~W} \mathrm{~m}^{-1} \mathrm{~K}^{-1}\right)$ \\
Thermal conductivity of absorber plate & $202.4\left(\mathrm{~W} \mathrm{~m}^{-1} \mathrm{~K}^{-1}\right)$ \\
Thermal conductivity of insulation material & $0.173\left(\mathrm{~W} \mathrm{~m}^{-1} \mathrm{~K}^{-1}\right)$ \\
Density of glass cover & $2530\left(\mathrm{~kg} \mathrm{~m}^{-3}\right)$ \\
Density of absorber plate & $2719\left(\mathrm{~kg} \mathrm{~m}^{-3}\right)$ \\
Density of insulation material & $700\left(\mathrm{~kg} \mathrm{~m}^{-3}\right)$ \\
\hline
\end{tabular}

○ Energy equation:

$\frac{\partial(\rho \mathrm{e})}{\partial \mathrm{t}}+\frac{\partial}{\partial \mathrm{x}_{\mathrm{j}}}\left(\rho \mathrm{v}_{\mathrm{i}} \mathrm{C}_{\mathrm{p}} \mathrm{T}-\mathrm{K} \frac{\partial \mathrm{T}}{\partial \mathrm{x}_{\mathrm{j}}}\right)=\mathrm{u}_{\mathrm{j}} \frac{\partial \mathrm{p}}{\partial \mathrm{x}_{\mathrm{j}}}+\left[\mu\left(\left(\frac{\partial \mathrm{v}_{\mathrm{i}}}{\partial \mathrm{x}_{\mathrm{j}}}+\frac{\partial \mathrm{v}_{\mathrm{j}}}{\partial \mathrm{v}_{\mathrm{i}}}\right)-\frac{2}{3} \frac{\partial \mathrm{v}_{\mathrm{k}}}{\partial \mathrm{x}_{\mathrm{k}}} \delta_{\mathrm{ij}}\right)\right]$

In the CFD analysis section, RNG K- $\varepsilon$ model by adding enhanced wall functions option has been applied in ANSYS Fluent software. The modeled transport equations for K and $\varepsilon$ in the K- $\varepsilon$ model are presented as follow:

$$
\begin{aligned}
& \frac{\partial(\rho \mathrm{K})}{\partial \mathrm{t}}+\frac{\partial\left(\rho \mathrm{Kv}_{\mathrm{i}}\right)}{\partial \mathrm{x}_{\mathrm{i}}}=\frac{\partial}{\partial \mathrm{x}_{\mathrm{j}}}\left[\left(\frac{\mu+\mu_{\mathrm{t}}}{\sigma_{\mathrm{k}}}\right) \frac{\partial \mathrm{K}}{\partial \mathrm{x}_{\mathrm{j}}}\right]+\mu_{\mathrm{t}}\left(\frac{\partial \mathrm{v}_{\mathrm{i}}}{\partial \mathrm{x}_{\mathrm{j}}}+\frac{\partial \mathrm{v}_{\mathrm{j}}}{\partial \mathrm{v}_{\mathrm{i}}}\right) \frac{\partial \mathrm{v}_{\mathrm{i}}}{\partial \mathrm{x}_{\mathrm{j}}}-\rho \varepsilon \\
& \frac{\partial(\rho \varepsilon)}{\partial \mathrm{t}}+\frac{\partial\left(\rho \varepsilon \mathrm{v}_{\mathrm{i}}\right)}{\partial \mathrm{x}_{\mathrm{i}}}=\frac{\partial}{\partial \mathrm{x}_{\mathrm{j}}}\left[\left(\frac{\mu+\mu_{\mathrm{t}}}{\sigma_{\varepsilon}}\right) \frac{\partial \varepsilon}{\partial \mathrm{x}_{\mathrm{j}}}\right]+\mathrm{C}_{1 \varepsilon} \frac{\varepsilon}{\mathrm{K}} \mu_{\mathrm{t}}\left(\frac{\partial \mathrm{v}_{\mathrm{i}}}{\partial \mathrm{v}_{\mathrm{j}}}+\frac{\partial \mathrm{v}_{\mathrm{j}}}{\partial \mathrm{v}_{\mathrm{i}}}\right) \frac{\partial \mathrm{v}_{\mathrm{i}}}{\partial \mathrm{v}_{\mathrm{j}}}-\mathrm{C}_{2 \varepsilon} \rho \frac{\varepsilon^{2}}{\mathrm{~K}}-\alpha \rho \frac{\varepsilon^{2}}{\mathrm{~K}} \\
& \mu_{\mathrm{t}}=\rho \mathrm{C}_{\mu} \frac{\mathrm{K}^{2}}{\varepsilon}
\end{aligned}
$$

Moreover, the DPPF solar collector efficiency was determined as follows:

First, the transferred energy from the absorber plate to the air is calculated trough the following equation:

$$
\dot{\mathrm{Q}}_{\mathrm{a}}=\dot{\mathrm{m}}_{\mathrm{air}} \mathrm{C}_{\mathrm{p}, \mathrm{air}}\left(\mathrm{T}_{\mathrm{out}}-\mathrm{T}_{\mathrm{in}}\right)
$$

where $\mathrm{C}_{\mathrm{p} \text {,air }}$ is the specific heat capacity of the air is obtained from the following equation:

$$
\mathrm{C}_{\mathrm{p}, \text { air }}=1009.26-4.040310^{-3} \mathrm{~T}+6.175910^{-4} \mathrm{~T}^{2}-4.09710^{-7} \mathrm{~T}^{3}
$$

Then, the thermal efficiency of the DPPF collector is expressed as the ratio of the absorbed energy by air to the solar irradiance:

$$
\eta_{\mathrm{DPPF}-\text { Collector }}=\frac{\dot{\mathrm{Q}}_{\mathrm{a}}}{\mathrm{A}_{\mathrm{abs}} \mathrm{I}}
$$

Moreover, to evaluate the difference between the actual temperature and the maximum possible value of air at the collector outlet, the heat exchange effectiveness (HEE) ratio $\left(\varepsilon_{\mathrm{HX}}\right)$ is calculated through the following equation (Kutscher 2016):

$$
\varepsilon_{\mathrm{HX}}=\frac{\mathrm{T}_{\text {out }}-\mathrm{T}_{\text {in }}}{\mathrm{T}_{\mathrm{abs}}-\mathrm{T}_{\text {in }}}
$$

\section{Boundary conditions}

The boundary conditions are specified to solve the continuity and momentum equations. The received solar radiation by the air solar collector was modeled by the means of the solar calculator in fair weather conditions (ANSYS FLUENT 13 User's Guide 2013). The air ambient temperature during the simulation day was taken as the collector inlet air temperature at the DPPF. It was equal to $288.5 \mathrm{~K}$. Three different inlet mass flow rates were simulated, namely, $0.008 \mathrm{~kg} \mathrm{~s}^{-1}, 0.012 \mathrm{~kg} \mathrm{~s}^{-1}$ and 
$0.016 \mathrm{~kg} \mathrm{~s}^{-1}$. The pressure boundary condition was applied at the outlet of the solar collector, as it is exposed to the surrounding atmosphere.

\section{Mesh dependency}

To ensure the accuracy of the simulation, a grid density test was performed for the considered DPPF air solar collector through repeated grid adaptation. Figure 4 depicts the variation of the absorber temperature as a function of the mesh number. The mesh size was varied from a coarser mesh of 560,606 to a finer size of 8,051,049. Reducing the mesh size increased the absorber temperature; However, after the third mesh density the absorber temperature remains constant. Therefore, a mesh number of 3,247,237 was adapted for this study for further computations. It is associated to a minimal mesh quality of 0.15 and a maximal skewness value of 0.85 .

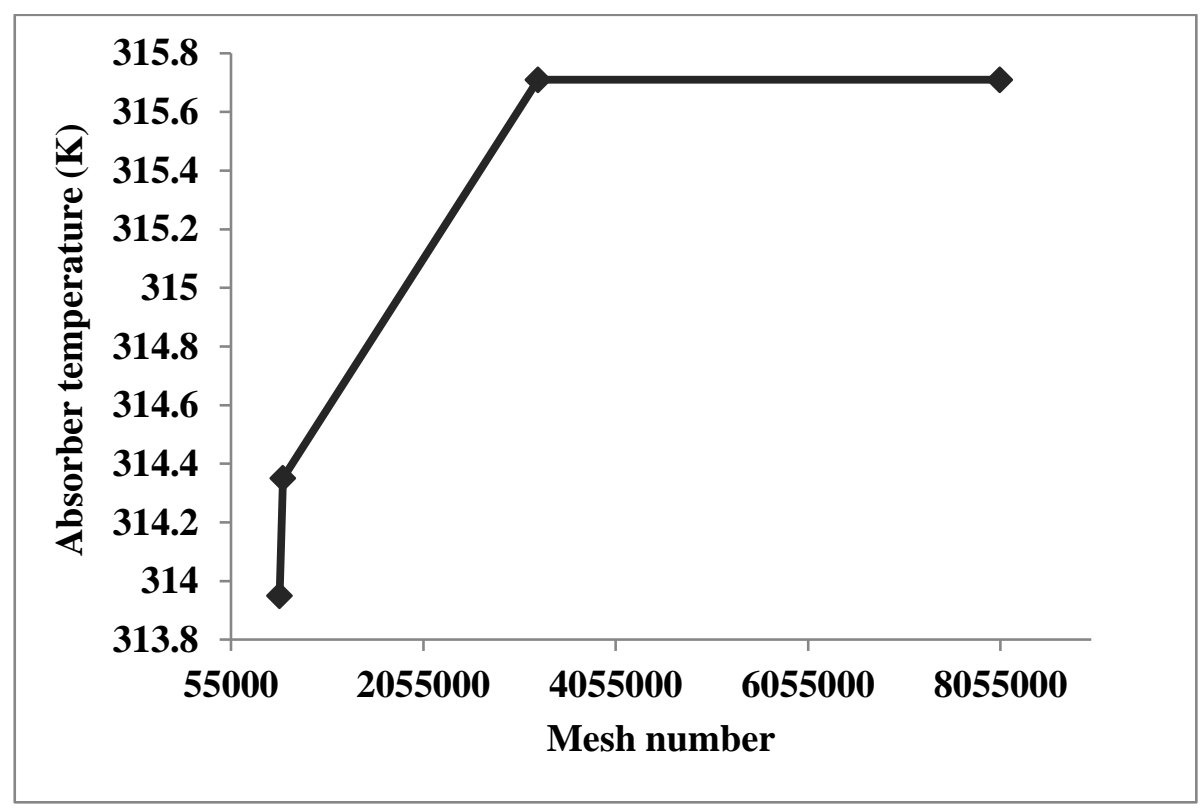

Figure. 4. Effect of mesh density on the absorber temperature

\section{RESULTS AND DISSCUSSION}

\section{DPPF solar collector numerical simulation}

The CFD simulation of the four configurations of the DPPF air solar collector was performed under the solar conditions of Marrakech. Three different air flows were simulated: $0.008 \mathrm{~kg} \mathrm{~s}^{-1}, 0.012$ $\mathrm{kg} \mathrm{s}^{-1}$ and $0.016 \mathrm{~kg} \mathrm{~s}^{-1}$. The temperature distribution in the air domain $2 \mathrm{~mm}$ over the absorber plate for these air flow rates is illustrated in Table 2. The incident solar radiation is absorbed by the DPPF collector absorber plate then transferred to the passing air. As the flow rate increases, the passing air doesn't have enough time to stay in contact with the absorber. Thus the air thermal energy gain decreases. In the first configuration (1) there is no obstacle in the air flow direction. Consequently, there is a laminar sub-layer over the absorber plate that lowers the heat transfer coefficient. In order to enhance the air contact and break the laminar sub-layer over the absorber plate, three modifications were simulated (Configurations (2-4)). The use of a perpendicular-air flow waved absorber plate doesn't have an efficient impact on the air temperature inside the DPPF solar collector (Table 2). Whereas a parallel-air flow waved absorber plate creates a barrier and causes an increase in the air outlet temperature. In this configuration, there are domes in the flow direction, which enable to enhance the heat transfer. In the fourth configuration, $\mathrm{V}$-corrugated modification was mounted on the upper side of the absorber plate. Adding V-corrugations has a significant positive effect and leads to 
higher air temperature. Table 3 gathers the velocity distribution in the air domain of the DPPF solar air collector. In the first and second configurations, air passes through the two sides of the flat plat absorber uniformly. In the other configurations, air velocity is much lower inside the DPPF collector compared to the previous configurations. As the air velocity decreases, the air residence time inside the collector increases. Therefore, air can gain more thermal energy inside the DPPF air solar collector.

Temperature distribution at the solar collector outlet is presented in Table 4. This Table shows the effect of the modification to the absorber plate on the heat transfer coefficient in the DPPF solar collector, which, as a consequence, modifies the air temperature value and distribution at the collector's outlet. For all configurations, the areas over the absorber plate have a higher temperature while the temperature down the absorber plate is low compared to the upper side and its distribution is uniform. The highest values of the temperature at the upper sides under the lowest mass flow rate of the four configurations are equal to $303.2 \mathrm{~K}, 298.9 \mathrm{~K}, 304 \mathrm{~K}$ and $318.9 \mathrm{~K}$, respectively. While the highest temperature values associated to the highest air mass flow of these configurations are equal to 295.9 K, 294.4 K, 297.8 K and 305.82 K, respectively.

Table 2. Temperature distribution in air domain $2 \mathrm{~mm}$ over the absorber plat

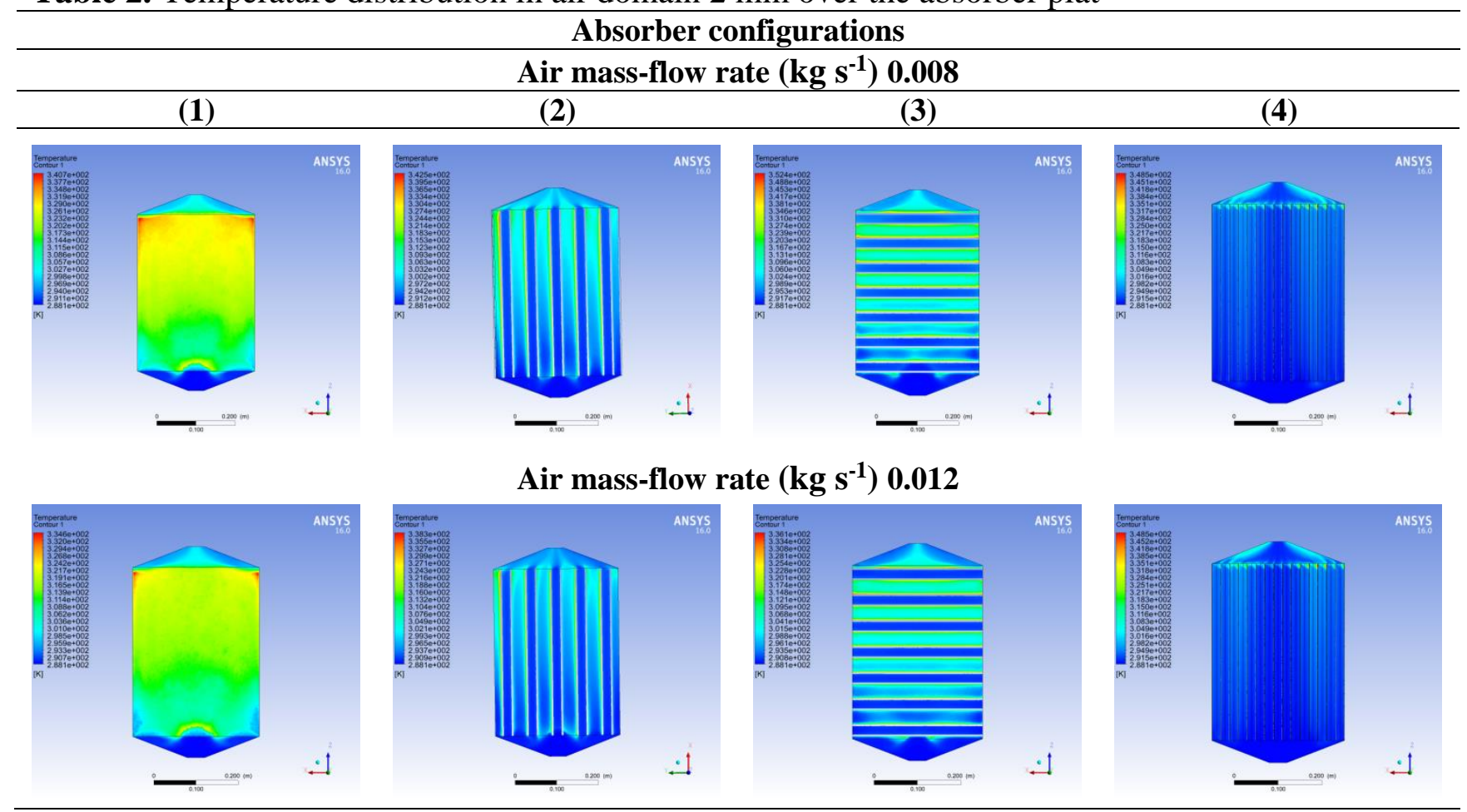

Table 2. Temperature distribution in air domain $2 \mathrm{~mm}$ over the absorber plat (continued)

\section{Air mass-flow rate $\left(\mathrm{kg} \mathrm{s}^{-1}\right) 0.016$}
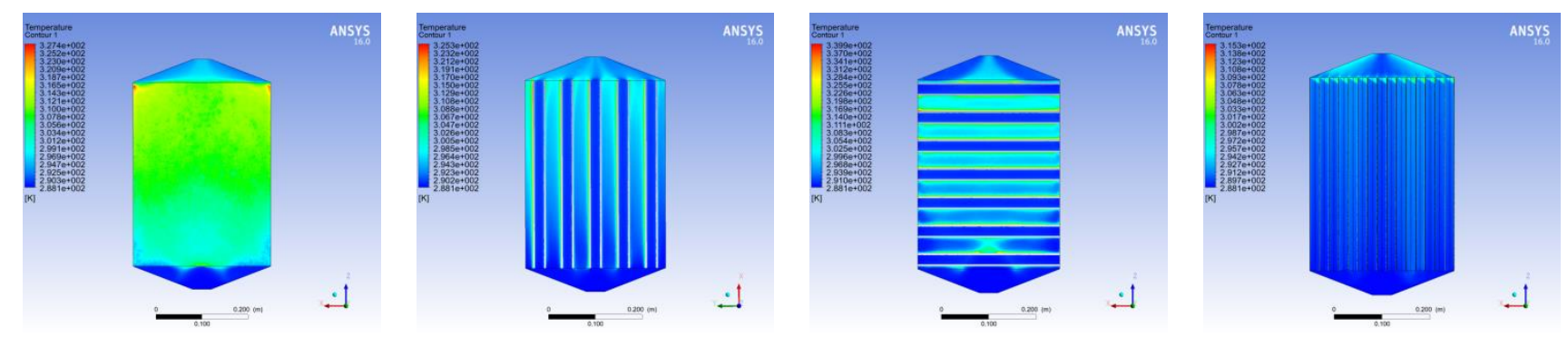


\begin{tabular}{|c|c|}
\hline Abderrahman MELLALOU et al. & $11(3): 2195-2207,2021$ \\
\hline Performance of an Air Solar Collector with Different Absorber Modifications Under the Climatic Conditions of Marrakech- \\
Morocco
\end{tabular}

Table 3. Velocity distribution inside the DPPF collector

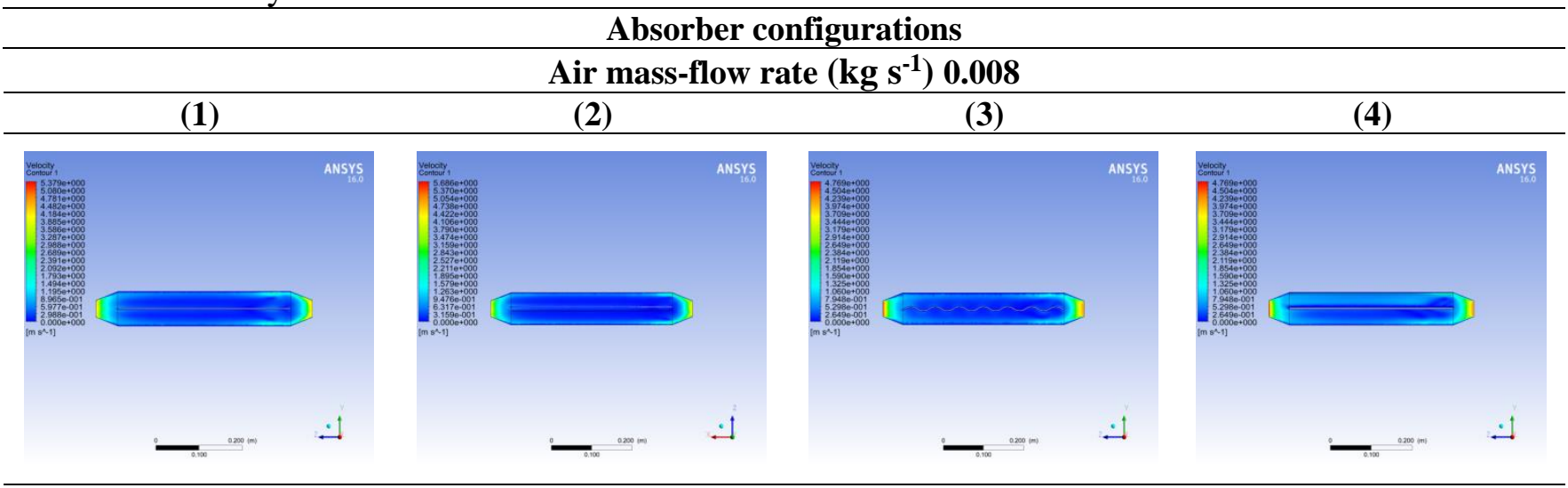

Air mass-flow rate $\left(\mathrm{kg} \mathrm{s}^{-1}\right) 0.012$

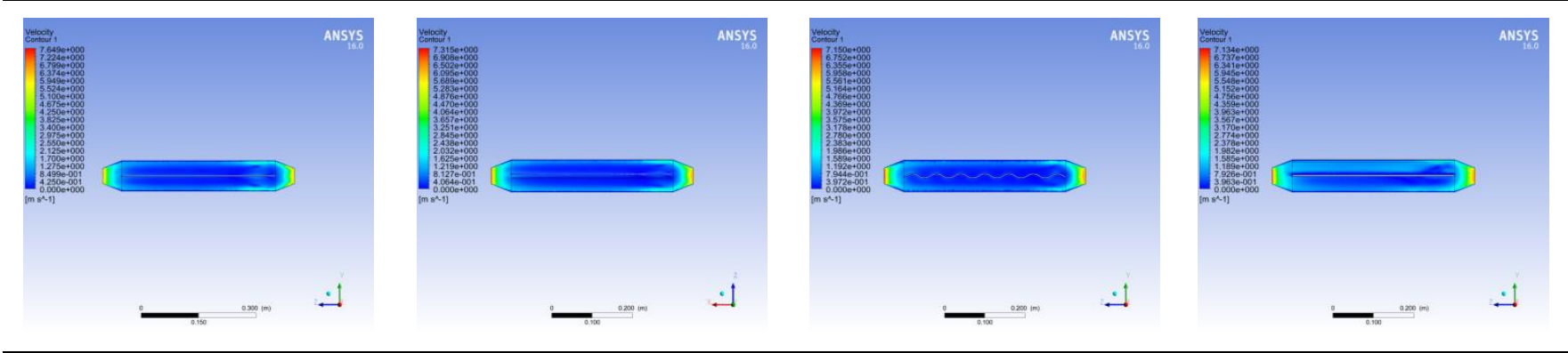

Air mass-flow rate $\left(\mathrm{kg} \mathrm{s}^{-1}\right) 0.016$
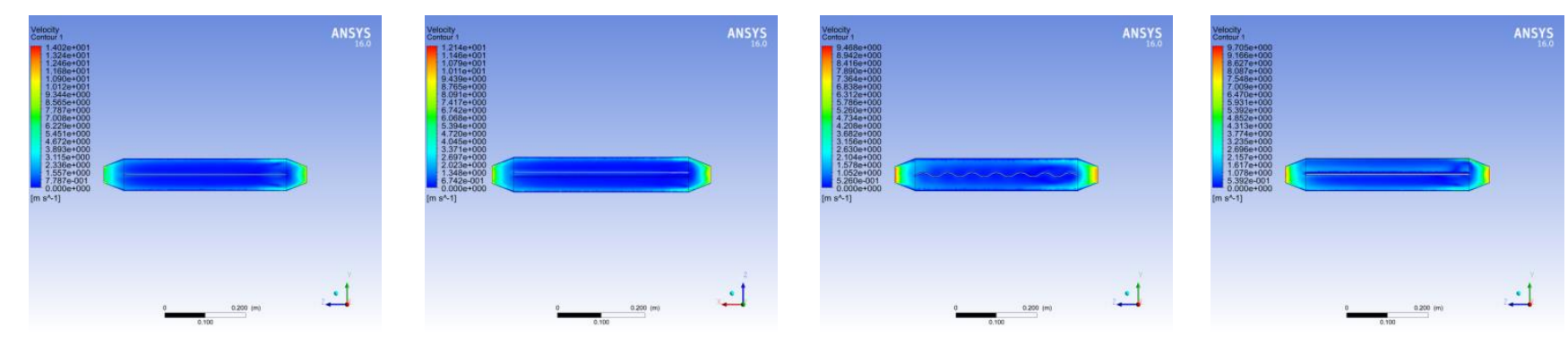

Figure 5 presents the air average outlet temperature variation under the three air mass-flow rates for the four configurations. The lowest increase in the air outlet temperature was found for the second configuration with $5.54 \mathrm{~K}, 4.26 \mathrm{~K}$ and $3.13 \mathrm{~K}$ under $0.008 \mathrm{~kg} \mathrm{~s}^{-1}, 0.012 \mathrm{~kg} \mathrm{~s}^{-1}$ and $0.016 \mathrm{~kg} \mathrm{~s}^{-1}$ air flow rates, respectively. While the highest increase in the outlet temperature was found for the $\mathrm{V}$-corrugated modification with $8.74 \mathrm{~K}, 6.40 \mathrm{~K}$ and $5.00 \mathrm{~K}$ under $0.008 \mathrm{~kg} \mathrm{~s}^{-1}, 0.012 \mathrm{~kg} \mathrm{~s}^{-1}$ and $0.016 \mathrm{~kg} \mathrm{~s}^{-1}$ air flow rates, respectively. Bhattacharyya et al. (2017) stated in their work that increasing the number of fins increases the air outlet temperature. This statement justifies the found results. Moreover, increasing the number of airflow passes also has a positive effect on increasing the air temperature at the collectors's outlet. 


\begin{tabular}{|c|c|}
\hline Abderrahman MELLALOU et al. & $11(3): 2195-2207,2021$ \\
\hline $\begin{array}{c}\text { Performance of an Air Solar Collector with Different Absorber Modifications Under the Climatic Conditions of Marrakech- } \\
\text { Morocco }\end{array}$ & \\
\hline
\end{tabular}

Table 4. Temperature distribution at DPPF collector outlet

Absorber configurations
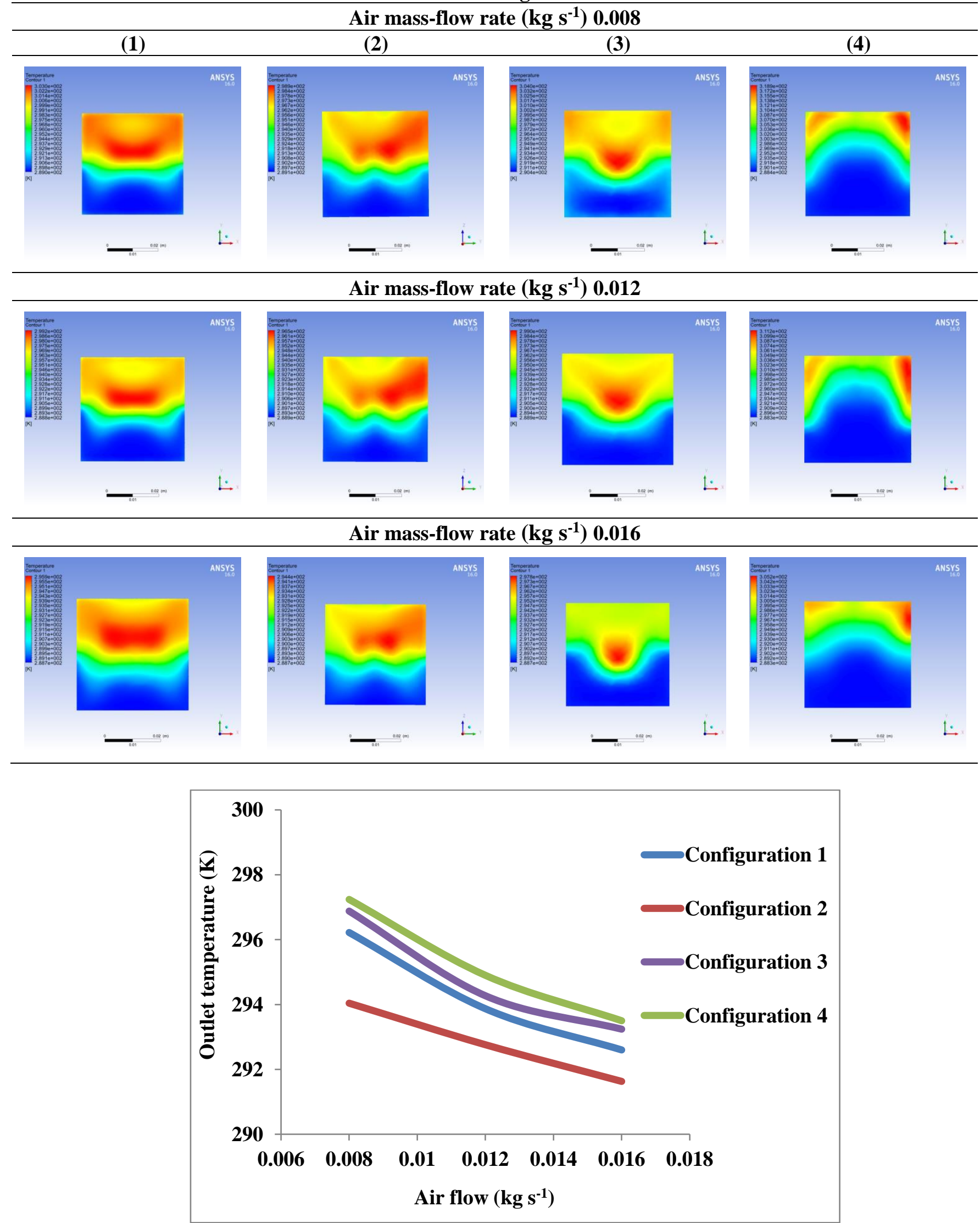

Figure. 5. Variation of the average outlet temperature with air flow rate for the 4 configurations 
The variation of the DPPF solar air collector's thermal efficiency with configurations is shown in Figure 6. As it can be seen, the thermal efficiency of all configurations is enhanced by increasing the air flow rate. The thermal efficiency of the four configurations under the lowest air flow rate of 0.008 $\mathrm{kg} \mathrm{s}^{-1}$ is $67.93 \%, 45.46 \%, 70.56 \%$ and $76.92 \%$, respectively. While their thermal efficiency associated to the highest air flow rate $\left(0.016 \mathrm{~kg} \mathrm{~s}^{-1}\right)$ is $72.13 \%, 51.36 \%, 79.79 \%$ and $87.97 \%$, respectively. Thus, the highest thermal efficiency was found to be equal to $87.97 \%$ associated with the highest air flow rate for the fourth configuration ( $\mathrm{V}$-corrugated modification). Adding this modification increased the exchange surface of the solar collector and also increased the residence time of air in the collector. Consequently, the heat transfer coefficient has increased and the thermal efficiency of the DPPF solar collector was enhanced. As it was stated by Lin et al. (2020) in their work, the solar air heater thermal efficiency with corrugated absorber modification is $9 \%$ higher than that of a plain absorber. Moreover, the separation of flows into several parallel flows was the preponderant reason for the better performances of the solar air heater.

Figure 7 presents the average heat exchange effectiveness ratio $\varepsilon_{\mathrm{HX}}$ of the four configurations. It is defined as the ratio of the heat transferred in the actual absorber configuration to the heat that would be transferred in the ideal absorber configuration. The HEE is related to the absorber design. Adding artificial roughness to the absorber plate increases the air residence time inside the collector and enlarges the heat exchange surface, creating, thus, the turbulence, which enhances the heat transfer coefficient and, by consequence, increases the HEE ratio. The CFD simulation results indicated that adding V-corrugated modification has a significant positive effect on the air outlet temperature and the thermal performance of the DPPF solar collector.

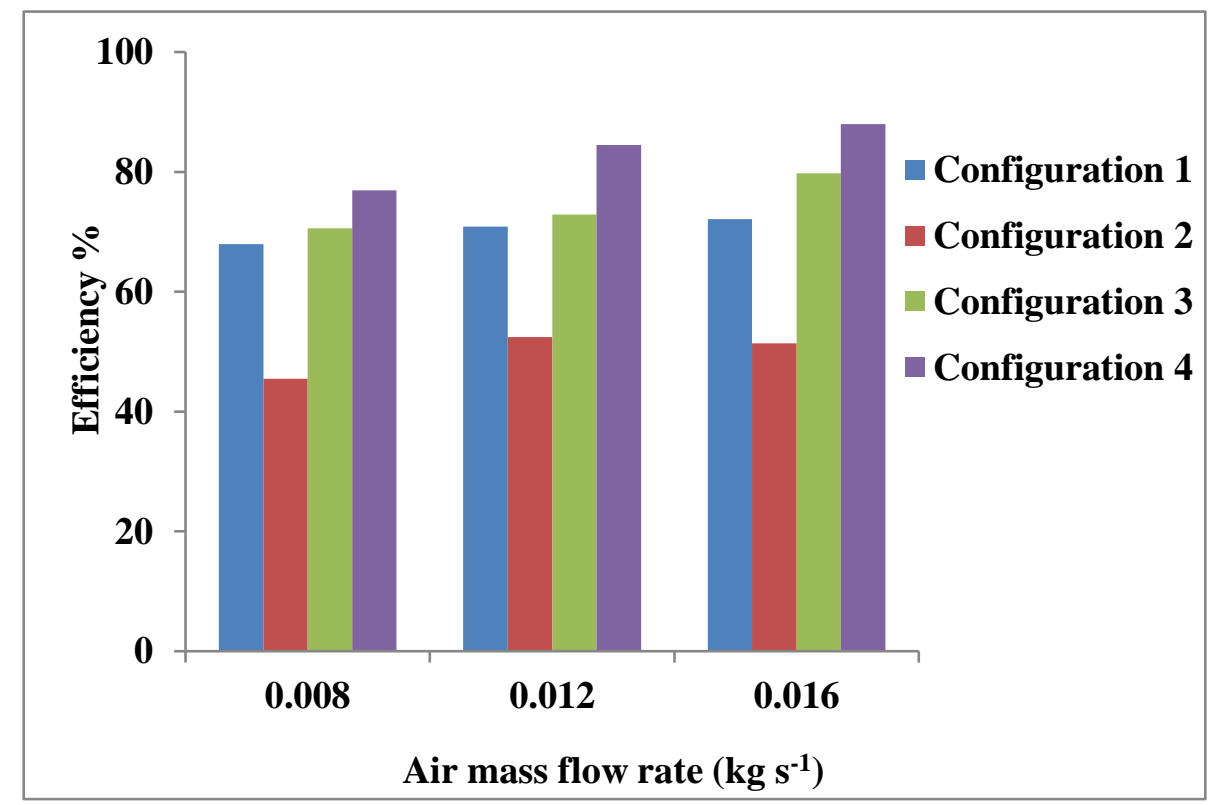

Figure. 6. The DPPF solar air collector thermal efficiency variation according to configurations 


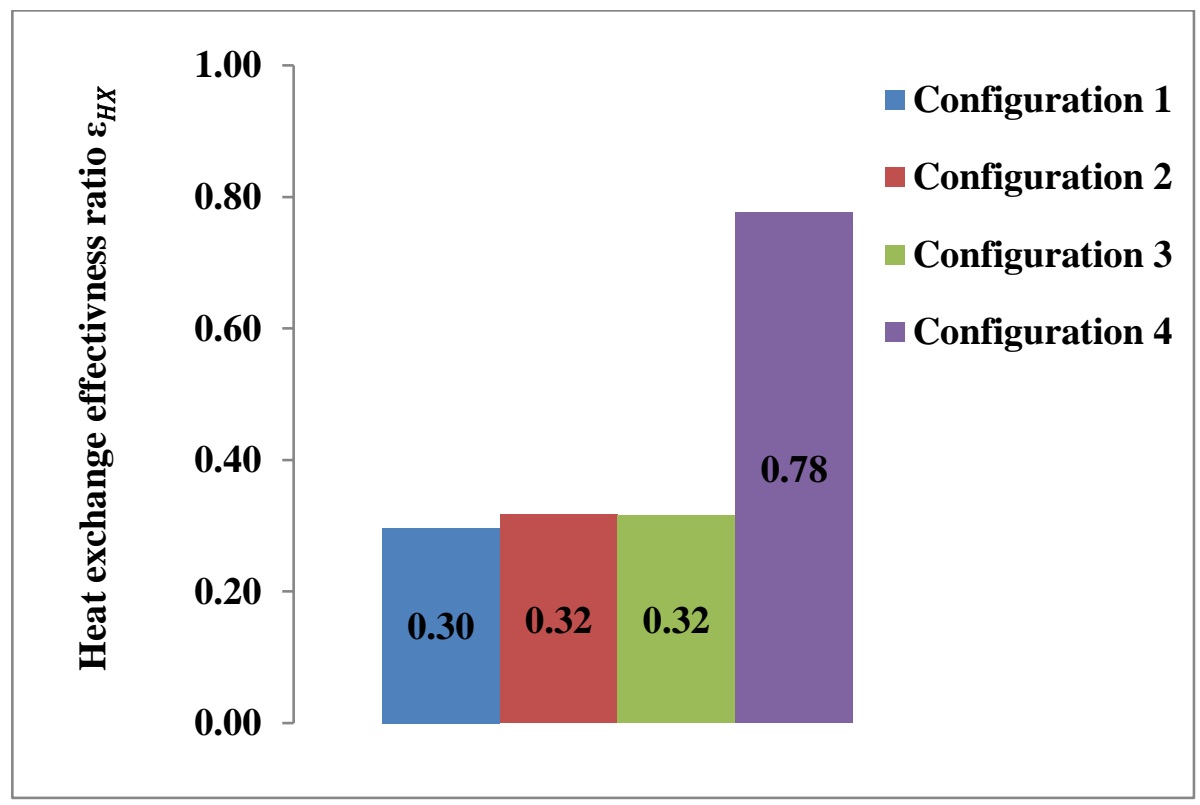

Figure. 7. Heat exchange effectiveness ratio variation via configurations

\section{CONCLUSION}

In this paper, the design and CFD analysis of four Double Pass Parallel Flow air solar collector configurations were carried out. The temperature distributions $2 \mathrm{~mm}$ over the absorber plate and at the DPPF collector outlet were evaluated. Moreover, the velocity field profiles were analyzed to predict the thermal efficiency of the solar collector. Adding artificial roughness to the absorber plate has a significant effect on the thermal performances of the DPPF collector. V-corrugated modification showed the high thermal performances for all mass flow rates with a thermal efficiency of $76.92 \%$, $84.46 \%$ and $87.97 \%$ under the air flow rate of $0.008 \mathrm{~kg} \mathrm{~s}^{-1}, 0.012 \mathrm{~kg} \mathrm{~s}^{-1}$ and $0.016 \mathrm{~kg} \mathrm{~s}^{-1}$, respectively. The results showed that the use of $\mathrm{V}$-corrugated shapes over the absorber plan in manufacturing air solar collectors is technically feasible. Thereby, it can be more beneficial to small scale thermal processes.

\section{ACKNOWLEDGEMENTS}

This work was performed in the frame of the Bioresol project. The authors are grateful to IRESEN for the financial support.

\section{Conflict of Interest}

There are no conflicts of interest.

\section{Author's Contributions}

The authors declare that they have contributed equally to the article

\section{REFERENCES}

ANSYS FLUENT 13 User's Guide. 2013. “Ansys Fluent Theory Guide.” ANSYS Inc., USA 15317(November): 724-46.

Bhattacharyya T, Anandalakshmi R, Srinivasan K, 2017. Heat Transfer Analysis on Finned Plate Air Heating Solar Collector for Its Application in Paddy Drying. Energy Procedia, 109: 353-60.

Chaube A, Sahoo PK, Solanki SC, 2006. Analysis of Heat Transfer Augmentation and Flow Characteristics Due to Rib Roughness over Absorber Plate of a Solar Air Heater. Renewable Energy, 31(3): 317-31. 
Ekechukwu OV, Norton B, 1999. Review of Solar-Energy Drying Systems II: An Overview of Solar Drying Technology. Fuel and Energy Abstracts, 40(3): 216.

Güler HÖ, Sözen A, Tuncer AD, Afshari F, Khanlari A, Şirin C, Gungor A, 2020. Experimental and CFD Survey of Indirect Solar Dryer Modified with Low-Cost Iron Mesh. Solar Energy 197: 37184.

Kishk SS., ElGamal RA, ElMasry GM, 2019. Effectiveness of Recyclable Aluminum Cans in Fabricating an Efficient Solar Collector for Drying Agricultural Products. Renewable Energy, 133: 307-16.

Kutscher CF, 2016. Heat Exchange Effectiveness and Pressure Drop for Air Flow Through Perforated Plates With and Without Crosswind. 116(May 1994): 391-99.

Lin W, Ren H, Ma Z, 2020. Mathematical Modelling and Experimental Investigation of Solar Air Collectors with Corrugated Absorbers. Renewable Energy, 145: 164-79.

Pashchenko DI, 2018. ANSYS Fluent CFD Modeling of Solar Air-Heater Thermoaerodynamics. Applied Solar Energy (English translation of Geliotekhnika) 54(1): 32-39.

Singh AP, Singh OP, 2018. Performance Enhancement of a Curved Solar Air Heater Using CFD. Solar Energy 174: 556-69.

Vengadesan E, Senthil R, 2020. A Review on Recent Developments in Thermal Performance Enhancement Methods of Flat Plate Solar Air Collector. Renewable and Sustainable Energy Reviews, 134: 110315.

Yadav AS, Bhagoria JL, 2013. A CFD (Computational Fluid Dynamics) Based Heat Transfer and Fluid Flow Analysis of a Solar Air Heater Provided with Circular Transverse Wire Rib Roughness on the Absorber Plate. Energy, 55: 1127-1142.

Yadav AS, Bhagoria JL, 2014. A Numerical Investigation of Square Sectioned Transverse Rib Roughened Solar Air Heater. International Journal of Thermal Sciences, 79: 111-31. 